\title{
Evaluation of Infectious Uveitis at a Tertiary Referral Center in Turkey: A 3 I-year Retrospective Study
}

\author{
Hasan Oncul, ${ }^{1}$ (1) Caner Kara, ${ }^{2}$ (i) Pinar Cakar Ozdal ${ }^{3}$ \\ 1Department of Ophthalmology, University of Health Sciences Gazi Yaşargil Training and Research Hospital, Diyarbakır, Turkey \\ 2Department of Ophthalmology, Etlik Zübeyde Hanim Women's Health Training and Research Hospital, Ankara, Turkey \\ ${ }^{3}$ Department of Ophthalmology, University of Health Scıences Ankara Ulucanlar Eye Research Hospital, Service of Uveitis and \\ Retinal Diseases, Ankara, Turkey
}

\begin{abstract}
Objectives: The aim of this study was to examine the demographic and clinical characteristics of patients with infectious uveitis over time.

Methods: The records of a total of 2032 patients treated for uveitis were retrospectively analyzed and 369 eyes of 324 patients diagnosed with infectious uveitis were included in the study. The patients were divided into 2 groups according to the date of presentation. The first group comprised patients seen between January 1988 and August 2009, and patients who presented between September 2009 and April 2019 were classified in the second group.

Results: The prevalence of infectious uveitis was $15.1 \%$ in the first group and $16.8 \%$ in the second group. A statistically significant decrease was observed in the number of toxoplasmosis patients in the second group $(p=0.03 \mathrm{I})$. There was no significant difference in the number of patients with herpetic anterior uveitis (HAU) $(p=0.215)$. A significant increase was recorded in the number of patients with tuberculosis and acute retinal necrosis (ARN) $(p=0.006$ and $p=0.041$, respectively). While there were no patients diagnosed with cytomegalovirus (CMV) anterior uveitis in the first group, 19 patients were diagnosed with the disorder in the second group. There was a decrease in the rate of legal blindness among the patients who were treated in the second period compared with the first period; however, this difference was not statistically significant $(p=0.069)$.

Conclusion: Toxoplasmosis and HAU were the 2 most common causes of infectious uveitis. The incidence of CMV anterior uveitis, tuberculosis-related uveitis, and ARN increased over the period studied.

Keywords: Epidemiology, herpes, infectious uveitis, toxoplasmosis, tuberculosis
\end{abstract}

\section{Introduction}

Uveitis is an ocular inflammatory disease that can develop as a result of infectious and non-infectious causes and accounts for as much as $25 \%$ of the reasons for blindness in the world (I). The statistical incidence of uveitis has increased, in part, due to improved diagnostic methods. The etiology and prev- alence of infectious uveitis varies depending on geographical location, demographic structure, and national socioeconomic status. While infectious uveitis constitutes I5\% to $20 \%$ of all uveitis cases in developed countries, the rate has been reported to be as much as $30.7 \%$ in developing countries $(I, 2)$.

Some types of uveitis are self-limiting, have a good prognosis, and do not require treatment. However, there are also

How to cite this article: Oncul H, Kara C, Cakar Ozdal P. Evaluation of Infectious Uveitis at a Tertiary Referral Center in Turkey: A 3 I-year Retrospective Study. Beyoglu Eye J 2021; 6(2): II5-123.

Address for correspondence: Hasan Oncul, MD. Saglik Bilimleri Universitesi Gazi Yasargil Egitim ve Arastirma Hastanesi, Goz Hastaliklari Anabilim Dali, Diyarbakır Turkey

Phone: +90 5357624011 E-mail: hasan.oncul@hotmail.com

Submitted Date: December 20, 2020 Accepted Date: April 03, 2021 Available Online Date: June 08, 2021

${ }^{\circ}$ Copyright 2021 by Beyoglu Eye Training and Research Hospital - Available online at www.beyoglueye.com OPEN ACCESS This work is licensed under a Creative Commons Attribution-NonCommercial 4.0 International License. 
more aggressive types that can lead to the development of legal blindness (3). The first phase of uveitis treatment is the distinction between infectious and non-infectious forms. This ensures that effective anti-infectious therapy is initiated early in the applicable patients, and that treatments such as steroids and immunosuppressants, which can worsen the course of the disease if used inappropriately, are avoided. However, the differential diagnosis of uveitis includes a wide range of disease and making an accurate diagnosis can be difficult, despite a detailed evaluation.

The ability to recognize possible causes of uveitis based on knowledge of the demographic, etiological, and clinical features will facilitate effective planning of the treatment process and better visual results. This study was designed to examine and present the demographic and clinical features of patients with a diagnosis of infectious uveitis who were treated at a tertiary reference eye center and to evaluate whether the clinical and demographic features had changed over time.

\section{Methods}

This study was performed retrospectively at the Uvea-Behçet Department of Ulucanlar Training and Research Hospital once approval had been granted by the Ethics Committee (22.05.2019/23). Patients diagnosed with infectious uveitis between January 1988 and April 2019 who were followed up for at least 6 months were included in the study. The patients were divided into 2 groups according to the date of diagnosis. Patients who were treated between January 1988 and August 2009 were classified as the first group, and the second group comprised those seen between September 2009 and April 2019. The files of 2032 patients were examined. In all, 369 eyes of 324 patients diagnosed with infectious uveitis according to clinical and/or laboratory findings were included in the study. Patients with decreased vision caused by other pathologies, such as senile macular degeneration, amblyopia, and diabetic retinopathy, and those with less than 6 months of follow-up were excluded.

Details of a detailed ophthalmological examination, including a best corrected visual acuity (BCVA) examination, biomicroscopic examination, intraocular pressure measurements, and a dilated fundus examination, were recorded from the patient files. Patients suspected of having infectious uveitis were screened using various protocols according to the clinical features. The eye fluid was analyzed in order to confirm the diagnosis in some cases. Serological tests were requested for patients when there was a clinical suspicion of toxoplasmosis, brucellosis, syphilis, or Lyme disease. Patients underwent additional consultations with the relevant department if there were chest disease, infectious disease, neurology or rheumatology concerns.
The uveitis classification of all of the study patients was made according to the criteria defined by the Standardization of Uveitis Nomenclature Project study group (4).

The BCVA findings of the first examination were used as the initial visual acuity level, and the BCVA results of the final examination were used to evaluate the degree of vision change. Legal blindness was defined as a BCVA of $\leq 0.1$ logarithm of the minimum angle of resolution or a visual field of $\leq 20^{\circ}$ according to the World Health Organization criteria (2).

\section{Statistical Analysis}

IBM SPSS Statistics for Windows, Version 23.0 software (IBM Corp., Armonk, NY, USA) was used to perform the statistical analysis. Categorical data were expressed as a number (n) and \%, and the quantitative data as the mean \pm SD (range). The distribution was evaluated with the Kolmogorov-Smirnov test. A t-test was used in binary comparisons of data that conformed to normal distribution and one-way analysis of variance was used in triple comparisons. The Mann-Whitney $U$ test was used in binary comparisons of data that did demonstrate a normal distribution, and the Kruskal-Wallis test was used in triple comparisons. A p value of $<0.05$ was considered statistically significant.

\section{Results}

In all, 369 eyes of 324 patients diagnosed with infectious uveitis according to the clinical and/or laboratory findings were included in the study. Of these, $142(43.8 \%)$ patients were male and $182(56.2 \%)$ were female. The mean age of the patients was $41.7 \pm 15.7$ years (range: $3-80$ years). The prevalence of infectious uveitis was $15.1 \%$ in the first group and $16.8 \%$ in the second group. The overall rate was $15.9 \%$.

The cause was toxoplasmosis in $135(41.7 \%)$ patients, herpetic anterior uveitis (HAU) in 127 (39.2\%), tuberculosis uveitis in $23(7.1 \%)$, cytomegalovirus (CMV) anterior uveitis in $19(5.9 \%)$, acute retinal necrosis (ARN) in II (3.4\%), toxocariasis in 4 (1.2\%), Lyme disease in $3(0.9 \%)$, and $2(0.6 \%)$ patients were diagnosed with brucellar uveitis.

A statistically significant decrease in cases of toxoplasmosis was observed in the second group $(p=0.03 \mathrm{I})$. There was no significant difference in the number of patients with HAU $(p=0.215)$; however, there was a significant increase in the number of patients with tuberculosis and ARN $(p=0.006$ and $p=0.04 \mathrm{I}$, respectively). While there were no patients diagnosed with CMV anterior uveitis in the first group, there were 19 cases in the second group. Posterior involvement decreased in the second group and panuveitis increased $(p<0.001$ for both). A comparison of demographic and clinical characteristics of the patients in the 2 time periods is provided in Table I. 
Table I. Demographic and clinical characteristics of the study patients

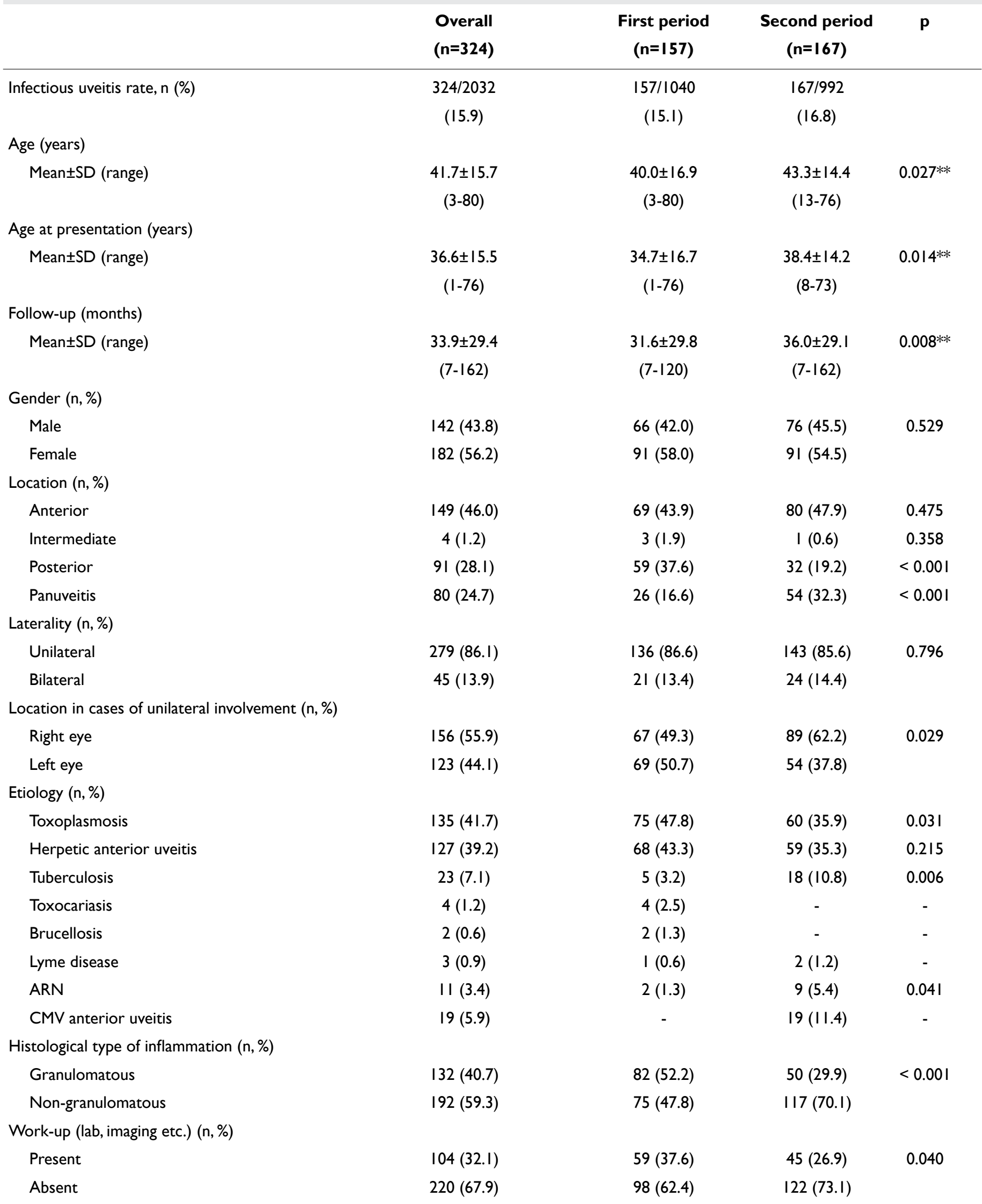


Table I. CONT.

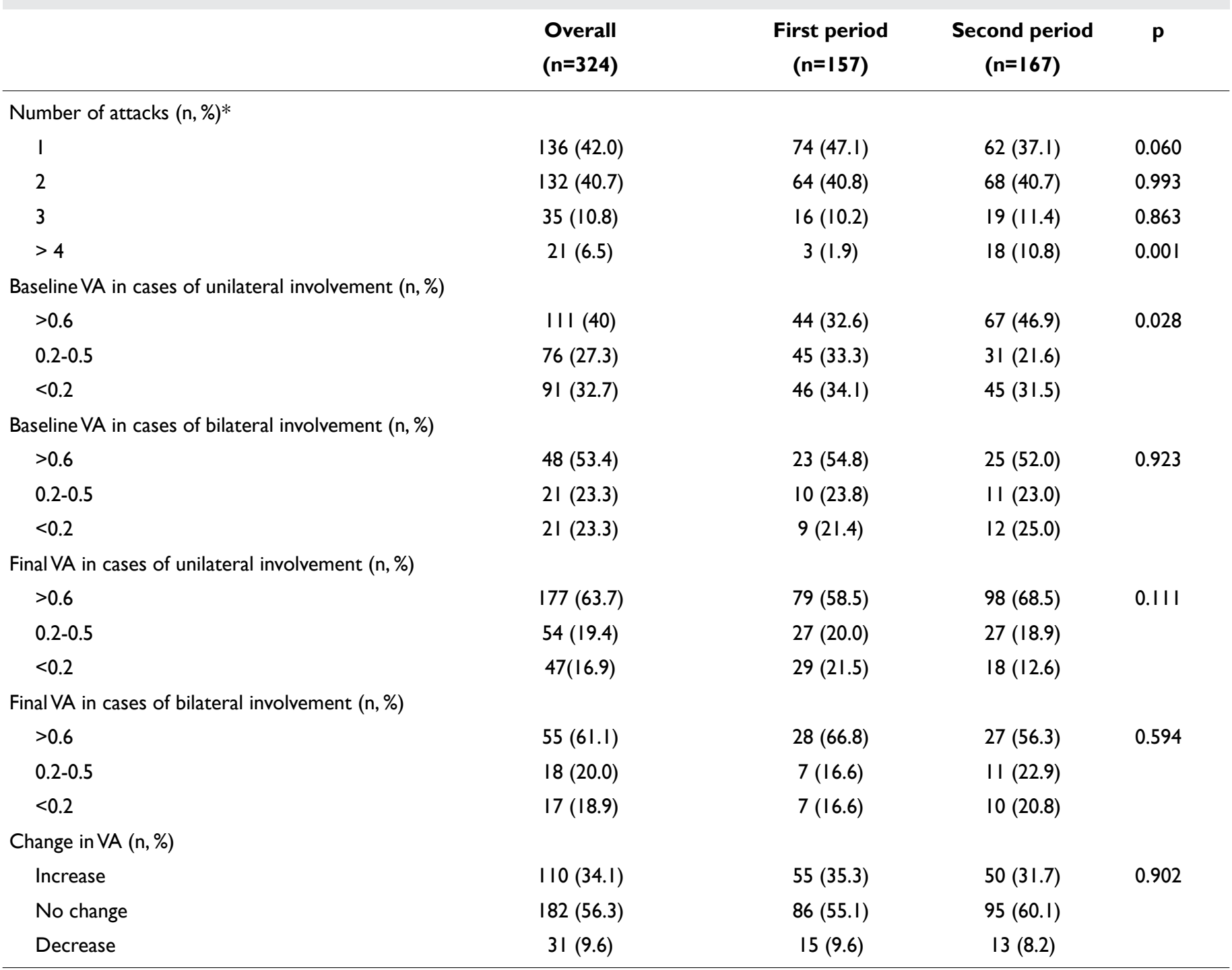

*: During the follow-up period; **: Mann-Whitney $U$ test; Visual acuity could not be obtained in a 3-year-old child with unilateral involvement;ARN:Acute retinal necrosis; CMV: Cytomegalovirus; VA:Visual acuity.

Visual acuity increased after treatment in $34.1 \%$ of the patients. There was no change in $56.3 \%$, and a decrease was observed in $9.6 \%$ of patients, despite treatment. The demographic and clinical characteristics of patients according to etiological agents are shown in Table 2.

One or more complications occurred during follow-up in $210(64.8 \%)$ of the patients: All of the patients with ARN experienced at least I complication, $84.3 \%$ of those with HAU, $78.9 \%$ of those with CMV anterior uveitis, $73.9 \%$ of those with tuberculosis uveitis, and $38.5 \%$ of the toxoplasmosis patients. Macular scarring (24.4\%), retinal vasculitis (14.1\%), macular edema (1I.9\%), and vitreous condensation (II.I\%) were the most common complications observed in the patients with toxoplasmosis. Anterior segment com- plications, such as glaucoma (28.3\%), iris atrophy (21.3\%), corneal opacity (20.5\%), and posterior synechiae (16.5\%) were common in patients with HAU. Among the patients with tuberculous uveitis, anterior segment complications of posterior synechiae (26.1\%) and cataracts (17.4\%), as well as posterior segment complications, such as macular edema (I3\%), epiretinal membrane (ERM) (I3\%), macular scarring (13\%), and vitreous condensation (13\%) occurred. While glaucoma (42.1\%), cataract (31.6\%), and iris atrophy (21.1\%) were seen in patients with CMV anterior uveitis, ERM (54.5\%), vitreous condensation (54.5\%), and retinal detachment $(54.5 \%)$ were common in patients with ARN. The complications and different etiological factors recorded are detailed in Table 3. 
Table 2. Demographic and clinical characteristics of the patients according to etiological agent

\begin{tabular}{|c|c|c|c|c|c|c|c|c|}
\hline & Toxoplasmosis & $\begin{array}{c}\text { Herpetic } \\
\text { anterior } \\
\text { uveitis }\end{array}$ & Tuberculosis & Toxocariasis & Brucellosis & $\begin{array}{l}\text { Lyme } \\
\text { disease }\end{array}$ & ARN & $\begin{array}{c}\text { CMV } \\
\text { anterior } \\
\text { uveitis }\end{array}$ \\
\hline $\begin{array}{l}\text { Number of } \\
\text { patients (n, \%) }\end{array}$ & $135(4 \mid .7)$ & 127 (39.2) & $23(7.1 \%)$ & $4(1.2)$ & $2(0.6)$ & $3(0.9)$ & II (3.4) & $19(5.9)$ \\
\hline \multicolumn{9}{|l|}{ Age (years) } \\
\hline Mean & $33.9 \pm 11.9$ & $49.6 \pm 15.1$ & $45.4 \pm 15.2$ & $19.3 \pm 3$ & $20.0 \pm 7.1$ & $41.3 \pm 26.6$ & $46.2 \pm 12.4$ & $45.8 \pm 14.5$ \\
\hline (Range) & $(3-7 I)$ & $(9-80)$ & $(17-75)$ & $(16-23)$ & $(15-25)$ & $(25-72)$ & $(25-64)$ & $(19-72)$ \\
\hline \multicolumn{9}{|l|}{$\begin{array}{l}\text { Age at presentation } \\
\text { (years) }\end{array}$} \\
\hline $\begin{array}{l}\text { Mean } \\
\text { (Range) }\end{array}$ & $\begin{array}{c}28.6 \pm 11.0 \\
(I-63)\end{array}$ & $\begin{array}{c}44.6 \pm 14.9 \\
(8-76)\end{array}$ & $\begin{array}{c}40.2 \pm 15.2 \\
(13-73)\end{array}$ & $\begin{array}{l}11.5 \pm 1.3 \\
(10-13)\end{array}$ & $\begin{array}{c}13.5 \pm 6.4 \\
(9-18)\end{array}$ & $\begin{array}{c}37.7 \pm 28.4 \\
(17-70)\end{array}$ & $\begin{array}{c}42.7 \pm 12.7 \\
(20-61)\end{array}$ & $\begin{array}{c}41.3 \pm 13.9 \\
(18-66)\end{array}$ \\
\hline \multicolumn{9}{|l|}{ Follow-up (months) } \\
\hline $\begin{array}{l}\text { Mean } \\
\text { (Range) }\end{array}$ & $\begin{array}{l}31.7 \pm 27 \\
(7-120)\end{array}$ & $\begin{array}{c}34.7 \pm 31.5 \\
(7-162)\end{array}$ & $\begin{array}{c}33.6 \pm 32.8 \\
(7-120)\end{array}$ & $\begin{array}{c}84.0 \pm 26.5 \\
(6 I-I I 8)\end{array}$ & $\begin{array}{l}I I .0 \pm 5.7 \\
(7-\mid 5)\end{array}$ & $\begin{array}{c}40.7 \pm 46.2 \\
(12-94)\end{array}$ & $\begin{array}{c}27.4 \pm 18.8 \\
(8-64)\end{array}$ & $\begin{array}{c}36.7 \pm 22.8 \\
(7-103)\end{array}$ \\
\hline \multicolumn{9}{|l|}{ Gender (n, \%) } \\
\hline Male & $43(31.9)$ & $64(50.4)$ & II (47.8) & $4(100)$ & $2(100)$ & 0 & $7(63.6)$ & II (57.9) \\
\hline Female & $92(68.1)$ & $63(49.6)$ & $12(52.2)$ & 0 & 0 & $3(100)$ & $4(36.4)$ & $8(42.1)$ \\
\hline \multicolumn{9}{|l|}{ Laterality (n, \%) } \\
\hline Unilateral & $115(85.2)$ & $120(94.5)$ & $8(34.8)$ & $4(100)$ & $2(100)$ & I (33.3) & II (100) & $18(94.7)$ \\
\hline Bilateral & $20(14.8)$ & $7(5.5)$ & $15(65.2)$ & - & - & $2(66.7)$ & 0 & I (5.3) \\
\hline \multicolumn{9}{|c|}{ Anatomical location (n, \%) } \\
\hline Anterior & 0 & $127(100)$ & $3(13)$ & 0 & 0 & 0 & 0 & $19(100)$ \\
\hline Intermediate & 0 & 0 & $4(17.4)$ & 0 & 0 & 0 & 0 & 0 \\
\hline Posterior & $81(60)$ & 0 & $2(8.7)$ & $3(75)$ & $\mathrm{I}(50)$ & $2(66.7)$ & $2(18.2)$ & 0 \\
\hline Panuveitis & $54(40)$ & 0 & $14(60.9)$ & $I(25)$ & $\mathrm{I}(50)$ & I (33.3) & $9(81.8)$ & 0 \\
\hline \multicolumn{9}{|l|}{ Histological type (n, \%) } \\
\hline Granulomatous & $38(28.1)$ & $58(45.7)$ & $23(100)$ & 0 & 0 & I (33.3) & $7(63.6)$ & $5(26.3)$ \\
\hline Non-granulomatous & $97(71.9)$ & $69(54.3)$ & 0 & $4(100)$ & $2(100)$ & $2(66.7)$ & $4(36.4)$ & $14(73.7)$ \\
\hline \multicolumn{9}{|c|}{ Mean number of attacks * } \\
\hline Mean (range) & $1.4 \mid(I-3)$ & $2.10(1-4)$ & $2.0(I-4)$ & $2.25(I-4)$ & 1 & $2.0(1-4)$ & $2.1(1-3)$ & $2.3(I-4)$ \\
\hline $\begin{array}{l}\text { Presence of ocular } \\
\text { complication(s) }(n, \%)\end{array}$ & $52 / 135(38.5)$ & I07/I27 (84.3) & 17 /23 (73.9) & $4 / 4(100)$ & $\mathrm{I} / 2(50.0)$ & $3 / 3(100)$ & $11 / 11(100)$ & $15 / 19(78.9)$ \\
\hline \multicolumn{9}{|c|}{ Change in final VA $(\mathrm{n}, \%) * *$} \\
\hline Increase & $53(39.5)$ & $40(31.5)$ & $6(26.1)$ & 0 & 0 & I (33.3) & $6(54.5)$ & $4(2 I .1)$ \\
\hline No change & $69(51.5)$ & $78(61.4)$ & $13(56.5)$ & $3(75.0)$ & $2(100.0)$ & I (33.3) & $2(18.2)$ & $14(73.6)$ \\
\hline Decrease & $12(9.0)$ & $9(7.1)$ & $4(17.4)$ & I (25.0) & 0 & I (33.3) & $3(27.3)$ & $\mathrm{I}(5.3)$ \\
\hline \multicolumn{9}{|l|}{ Legal blindness (n, \%) } \\
\hline Present & $30 / 135$ (22.2) & $19 / 127(15)$ & $5 / 23(21.7)$ & $2 / 4(50.0)$ & $\mathrm{I} / 2(50.0)$ & $\mathrm{I} / 3(33.3)$ & $5 / 11(45.5)$ & $1 / 19(5.3)$ \\
\hline
\end{tabular}


Table 3. Ocular complication(s) according to etiological factors.

Toxoplasmosis

Corneal opacities $(n=26,8.0 \%)$

Absent

Present

Iris atrophy $(n=32,9.9 \%)$

Absent

Present

Posterior synechia $(n=29.9 .0 \%)$

Absent

Present

Cataract $(n=25,7.7 \%)$

Absent

Present

Glaucoma ( $n=46,14.2 \%)$

Absent

Present

Macular edema $(n=25,7.7 \%)$

Absent

Present

$\operatorname{ERM}(n=19,5.9 \%)$

Absent

Present

Macular scarring $(n=36,11.1 \%)$

Absent

Present

Vitreous condensation $(n=30,9.3 \%)$

Absent

Present

Retinal detachment $(n=8,2.5 \%)$

Absent

Present

Retinal vasculitis ( $n=26,8.0 \%$ )

Absent

Present

Retinal vein occlusion $(n=I, 0.3 \%)$

135

0

135

0

133

2

134

I

135

0

119

16

129

6

102

33

120

15

133

2

116

19

Absent

Present

Herpetic Tuberculosis Toxocariasis anterior

uveitis

127

101

26

0

100

27

106

21

116

I I

91

36

127

0

127

0

23

4
0

2

0

Lyme

ARN disease

ARN

CMV anterior uveitis

19

19


Legal blindness developed in 64 (19.8\%) patients, despite treatment: $22.2 \%$ of the toxoplasmosis patients, $15.0 \%$ of those with $\mathrm{HAU}, 21.7 \%$ of those with tuberculosis uveitis, $5.3 \%$ of those with CMV anterior uveitis, and $45.5 \%$ of the ARN patients. Macular scarring and corneal lesions were the most common causes of legal blindness. There was a decrease in the rate of legal blindness in the second period; however, the difference was not statistically significant $(p=0.069)$.

\section{Discussion}

The rate of infectious uveitis differs according to the sociodemographic structure and development level of the country under study. In studies conducted at different times in Turkey, Sengun et al. (5) reported a frequency of $13.6 \%$ and Kazokoglu et al. (6) recorded a rate of $8.6 \%$. Recent analysis of 6963 eyes of 4863 patients in a multicenter national database in Turkey yielded a rate of $15.6 \%$ (7). Infectious uveitis was diagnosed in $30 \%$ of total uveitis cases in Italy, $29.7 \%$ in India, and 19\% in the USA (8-10). The prevalence determined in an evaluation of 8759 patients in 24 studies from different countries was $30.7 \%$ (I).

Luca et al. (8) examined uveitis patients in Italy from 2 time periods, as in our study. In 1064 uveitis cases followed in the first period (2002-2008), the rate of infectious uveitis was $24.1 \%$. In the second period (2013-2015), the prevalence recorded in 990 cases was $30.4 \%$. In the current study, the rate of infectious uveitis was $15.1 \%$ in 1040 patients who were followed up in the first period (2I years: 1988-2009). In the second group, ( 10 years: 2009-2019), the rate was $16.8 \%$ in 992 patients. The size of the patient group in the shorter second period may be related to the increasing number of patients overall, the fact that the study institution is a referral center, improved diagnostic techniques, and an increased level of awareness.

The most common cause of infectious uveitis may also differ according to the region studied. In research conducted in Turkey, toxoplasmosis and HAU have been identified as the most common causes of infectious uveitis (5-7). However, in the relatively less developed and animal husbandry-based Eastern Anatolia region, agents such as brucellosis and leprosy have been reported to be the most common causes of infectious uveitis (II). This regional distinction within a country is important. In this study, toxoplasmosis (4I.7\%) and HAU (39.2\%) were found to be the most common causes of infectious uveitis in the study group. The incidence of both decreased in the second period. The change was statistically significant in toxoplasmosis patients, while it was not significant in HAU patients. Patients with HAU are still frequently referred to referral hospitals. There was an increase in tuberculosis uveitis and ARN patients in the second group. In addition, CMV anterior uveitis was only seen in the second period of the study, which is noteworthy. We think that the increase in tuberculosis-induced uveitis and ARN patients in the later time period was at least in part due to the fact that our clinic became the local referral center for such cases. The increase in CMV anterior uveitis was likely related to improved diagnostic techniques and increased awareness.

Ocular toxoplasmosis is the most common cause of posterior uveitis. An earlier study conducted in Turkey (6) reported toxoplasmosis in $54.5 \%$ of infectious uveitis cases, while another found a rate of $45.1 \%$ (7). We recorded a toxoplasmosis rate of $41.7 \%$. The decrease in the toxoplasmosis rate observed in the second period (from $47.8 \%$ to $35.9 \%$ ) is notable. The decrease is thought to be related to the fact other centers were able to diagnose these cases on initial presentation without referring them to our clinic.

HAU is a common cause of infectious uveitis and has been reported to account for $10 \%$ of all uveitis cases at referral hospitals (I). Aqueous humor analysis plays an important role in defining the factor and the severity of the disease (I2). Lelij et al. (I3) reported that polymerase chain reaction (PCR) examination of the aqueous humor in patients without a history of keratitis but with recurrent attacks of anterior uveitis and sectoral iris atrophy determined that $83 \%$ of the patients were infected with herpes simplex virus (HSV). Among 112 eyes of 109 HAU patients diagnosed by Neumann et al. (I2) in a multicenter study, HSV was found in 54 (48.2\%), varicella zoster virus (VZV) in 34 (30.4\%), and CMV in $2(1.8 \%)$ patients; in 22 (19.6\%) no effective agent was determined. HAU was detected in $27.3 \%(6)$ and $38.5 \%$ (7) of patients with infectious uveitis in 2 studies performed in Turkey. In the current study, the rate of HAU among the entire study group was $39.2 \%$. The proportional decrease in patients with $\mathrm{HAU}$ in the second period (from $43.3 \%$ to $35.3 \%$ ) is clear, but was not statistically significant. This suggests that HAU cases still need to be treated at referral centers.

CMV anterior uveitis is a relatively recently understood cause of morbidity as a chronic recurrent disease. Approximately $25 \%$ of hypertensive anterior uveitis is thought to be a result of CMV infection, and no pathology may be evident in immunocompetent individuals (14). In a study published in Turkey in 2008 (6) that examined referral patterns and clinical features of uveitis, there was no identification of patients with CMV anterior uveitis, and research from 2016 (7) reported a CMV anterior uveitis rate of only $0.5 \%$ among patients with infectious uveitis. CMV anterior uveitis has been reported to account for two-thirds of viral anterior uveitis cases in Singapore and Thailand (15, 16), 39\% in Japan (17), and $4.8 \%$ in Italy (18). None of our patients were diagnosed with CMV anterior uveitis in the first group, however, the 
rate was $1 \mathrm{I} .4 \%$ in the second period. In $68.4 \%$ of these patients, the diagnosis was made using PCR testing. Among the patients we studied, the first diagnosis of CMV anterior uveitis was made after PCR analysis of anterior chamber fluid in June 20I3, when CMV-type keratic precipitates were seen in a patient who had been followed up for herpetic uveitis + secondary glaucoma since October 2010. We think that the difference seen between the 2 time periods is associated with improved diagnostic techniques and clinical experience as well as increased awareness of CMV anterior uveitis. Previously, these patients were frequently diagnosed as either Posner-Schlossman syndrome and followed-up with glaucoma treatment or the disease was misclassified as HAU. It is possible that some CMV anterior uveitis patients were categorized as herpetic uveitis in our first study group.

Tuberculosis uveitis can still be difficult to diagnose due to the fact that patients may have no pulmonary or other systemic involvement and the lack of standard diagnostic criteria. A good response to antituberculosis treatment and the absence of recurrence support the diagnosis $(19,20)$. The incidence of tuberculosis uveitis has been reported to be $10.5 \%$ in some endemic regions (2I), while $4.3 \%$ and $4.5 \%$ have been recorded in Turkey $(6,7)$. Luca et al. (8) also examined 2 time periods and observed that the number of patients with tuberculosis uveitis increased over time $(4.4 \%$ to $5.7 \%)$, but that the increase was not statistically significant. In the current study, tuberculosis uveitis was observed in 5 (3.2\%) patients in the first group and a significant increase was seen in the second group ( 18 patients, $10.8 \%$ ). This has been associated with an increase in tuberculosis infections in recent years and awareness of clinical findings suggestive of ocular tuberculosis.

ARN is caused by VZV, HSV I/2, and rarely, CMV. The prognosis is frequently poor, and may include retinal detachment and severe vision loss, despite intensive antiviral therapy (22). The development of invasive diagnostic techniques has offered the possibility of early diagnosis. PCR analysis of eye fluid is a quick and sensitive method to diagnose ARN (23).

In a study conducted in Turkey, ARN was detected in $6.1 \%$ of cases with infectious uveitis (6), and $2.8 \%$ in another study (7). In England, the annual ARN incidence was reported to be I in I.6-2.0 million people (24). We noted 2 (I.3\%) patients diagnosed with ARN in the first period and 9 (5.4\%) in the second period. This is likely due to increased use of our institution as a referral center in the second time period as well as more use of PCR testing. The clinical diagnosis was supported by PCR in 7 of II patients $(63.6 \%)$ diagnosed with ARN.

Laboratory tests provide clinicians with important clues for a differential diagnosis and atypical cases that cannot be diagnosed. Antibody tests are used in toxoplasmosis and toxocariasis cases, and cultures and staining are used in bacterial, fungal, and nocardial infections. PCR analysis provides significant advantages in the diagnosis of tuberculosis uveitis and viral retinitis. Invasive intraocular tests can be used, such as the analysis of vitreous fluid obtained via diagnostic pars plana vitrectomy, especially in cases where a diagnosis has not been confirmed and the disease worsens, despite treatment (25). In the current study, invasive and non-invasive tests were used to diagnose $32.1 \%$ of patients. This suggests that in most cases of infectious uveitis, the diagnosis can be made using clinical findings.

Uveitis is one of the leading causes of preventable blindness. The prevalence of legal blindness varies in different parts of the world due to local factors and the duration of the diagnosis. Some agents are known to have a higher risk of legal blindness than others. Yeo et al. (26) evaluated visual loss associated with uveitis and found that the rate of legal blindness was no greater in patients with infectious uveitis than other types of uveitis. In the current study, legal blindness developed in $19.8 \%$ of patients, despite treatment.

The epidemiological knowledge of uveitis continues to expand, as a result of the definition of new factors, population increases, migration between countries, increased awareness, and the development of new diagnostic techniques. The infectious/non-infectious distinction is of great importance in the diagnosis of uveitis. If this identification is not made correctly, adverse reactions to treatment can occur, as well as chronic disease, and potentially irreversible complications. Extensive examination and evaluation of the clinical symptoms of suspected infectious uveitis cases, appropriate interpretation of the accompanying history and demographic information, and confirmation as necessary using laboratory analysis are of great value in the early diagnosis and prevention of complications. A multidisciplinary approach and the use of appropriate and carefully selected treatment agents can reduce the prospect of complications.

\section{Disclosures}

Ethics Committee Approval: Etlik Zübeyde Hanim Women's Health Training and Research Hospital, 22.05.2019/23.

Peer-review: Externally peer-reviewed.

Conflict of Interest: None declared.

Authorship Contributions: Involved in design and conduct of the study (PCO, HO); preparation and review of the study ( $\mathrm{HO}, \mathrm{PCO}$, $\mathrm{CK})$; data collection (HO, CK); and statistical analysis (CK, HO).

\section{References}

I. Rathinam SR, Namperumalsamy P. Global variation and pattern changes in epidemiology of uveitis. Indian J Ophthalmol 2007;55: 173-83. [CrossRef]

2. Rothova A, Suttorp-van Schulten MS, Frits Treffers W, Kijlstra A. Causes and frequency of blindness in patients with intraocular 
inflammatory disease. Br J Ophthalmol 1996;80:332-6. [CrossRef]

3. McCannel CA, Holland GN, Helm CJ, Cornell PJ, Winston JV, Rimmer TG. Causes of uveitis in the general practice of ophthalmology. Ucla community-based uveitis study group. Am J Ophthalmol 1996;121:35-46. [CrossRef]

4. Jabs DA, Nussenblatt RB, Rosenbaum JT. Standardization of uveitis nomenclature working g. Standardization of uveitis nomenclature for reporting clinical data. Results of the first international workshop. Am J Ophthalmol 2005; 140:509-16. [CrossRef]

5. Sengun A, Karadag R, Karakurt A, Saricaoğlu MS, Abdik O, Hasiripi $H$. Causes of uveitis in a referral hospital in Ankara, Turkey. Ocul Immunol Inflamm 2005; I3:45-50. [CrossRef]

6. Kazokoglu H, Onal S, Tugal-Tutkun I, Mirza E, Akova Y, Ozyazgan $Y$, et al. Demographic and clinical features of uveitis in tertiary centers in Turkey. Ophthalmic Epidemiol 2008; 15:285-93.

7. Yalcindag FN, Ozdal PC, Ozyazgan Y, Batıoğlu F, Tugal-Tutkun I; BUST Study Group. Demographic and clinical characteristics of uveitis in turkey: The first national registry report. Ocul Immunol Inflamm 2018;26:17-26. [CrossRef]

8. Luca C, Raffaella A, Sylvia M, Valentina M, Fabiana V, Marco C, et al. Changes in patterns of uveitis at a tertiary referral center in Northern Italy: analysis of 990 consecutive cases. Int Ophthalmol 2018;38:I33-42. [CrossRef]

9. Zheng Y, Zhang LX, Meng QL, Zhang M, Cui Y, Liu QY, et al. Clinical patterns and characteristics of uveitis in a secondary hospital in southern China. Int J Ophthalmol 20I5;8:337-4I.

10. Glasner PD, Silveira C, Kruszon-Moran D, Martins MC, Burnier Júnior $M$, Silveira $S$, et al. An unusually high prevalence of ocular toxoplasmosis in southern Brazil. Am J Ophthalmol 1992; | | 4:136-44. [CrossRef]

I I. Gül A, Kılıç A, Yener HI, Demirok A, Çinal A. Van ve çevresindeki İllerin (Ağrı, Iğdır, Muş, Bitlis, Hakkâri) üveit verileri. Turk J Ophthalmol 2010;40:93-6.

12. Neumann R, Barequet D, Rosenblatt A, Amer R, Ben-ArieWeintrob $Y$, Hareuveni-Blum $T$, et al. Herpetic anterior uveitis - analysis of presumed and PCR proven cases. Ocul Immunol Inflamm 2019;27:211-8. [CrossRef]

13. Van der Lelij A, Ooijman FM, Kijlstra A, Rothova A. Anterior uveitis with sectoral iris atrophy in the absence of keratitis: a distinct clinical entity among herpetic eye diseases. Ophthalmology 2000; 107: I 164-70. [CrossRef]

14. Park SW, Yu HG. Association of cytomegalovirus with idiopathic chronic anterior uveitis with ocular hypertension in Korean patients. Ocul Immunol Inflamm 2013;21:192-6. [CrossRef]

15. Kongyai N, Sirirungsi W, Pathanapitoon K, Tananuvat N, Kunavisarut $\mathrm{P}$, Leechanachai $\mathrm{P}$, et al. Viral causes of unexplained anterior uveitis in Thailand. Eye (Lond) 2012;26:529-34. [CrossRef]

16. Chee SP, Bacsal K, Jap A, Se-Thoe SY, Cheng CL, Tan BH. Clinical features of cytomegalovirus anterior uveitis in immunocompetent patients. Am J Ophthalmol 2008; 145:834-40. [CrossRef]

17. Takase H, Kubono R, Terada Y, Imai A, Fukuda S, Tomita M, et al. Comparison of the ocular characteristics of anterior uveitis caused by herpes simplex virus, varicella-zoster virus, and cytomegalovirus. Jpn J Ophthalmol 2014;58:473-82. [CrossRef]

18. Miserocchi E, Waheed NK, Dios E, Christen W, Merayo J, Roque $M$, et al. Visual outcome in herpes simplex virus and varicella zoster virus uveitis: a clinical evaluation and comparison. Ophthalmology 2002; 109:1532-7. [CrossRef]

19. Gupta A, Sharma A, Bansal R, Sharma K. Classification of intraocular tuberculosis. Ocul Immunol Inflamm 20I5;23:7-I3. [CrossRef]

20. Özdal PÇ, Tekin K, Özateş S. Oküler tüberkülozun tanı ve tedavisinde güncel yaklaşımlar: Olgu serisi ve literatürün gözden geçirilmesi. Retina-Vitreus 2016;24:99-108.

2I. Islam SM, Tabbara KF. Causes of uveitis at the eye center in saudi arabia: A retrospective review. Ophthalmic Epidemiol 2002;9:239-49. [CrossRef]

22. Hafidi M, Janin-Manificat H, Denis P, Charleux B, Rabilloud M, Boibieux $A$, et al. Acute retinal necrosis: virological features using quantitative polymerase chain reaction, therapeutic management, and clinical outcomes. Am J Ophthalmol 2019;208:37686. [CrossRef]

23. Roy R, Pal BP, Mathur G, Rao C, Das D, Biswas J. Acute retinal necrosis: Clinical features, management and outcomes-a 10 year consecutive case series. Ocul Immunol Inflamm 2014;22: I70-4. [CrossRef]

24. Muthiah MN, Michaelides M, Child CS, Mitchell SM. Acute retinal necrosis: a national population-based study to assess the incidence, methods of diagnosis, treatment strategies and outcomes in the UK. Br J Ophthalmol 2007;91:|452-5. [CrossRef]

25. Jeroudi A, Yeh S. Diagnostic vitrectomy for infectious uveitis. Int Ophthalmol Clin 2014;54:173-97. [CrossRef]

26. Yeo TK, Ho SL, Lim WK, Teoh SC. Causes of visual loss associated with uveitis in a singapore tertiary eye center. Ocul Immunol Inflamm 2013;21:264-9. [CrossRef] 